\title{
The Cornell Leadership Program for Veterinary Students
}

\author{
Douglas D. McGregor • David R. Fraser
}

\begin{abstract}
Cornell University hosts a summer program for veterinary students who aspire to research careers. The program features independent, faculty-guided research; vocational counseling; and professional enrichment activities that seek to build teamwork skills and to foster critical thinking and effective communication. A total of 255 students from 49 veterinary colleges worldwide have taken part in the program since 1990. Among those who have completed their veterinary education, approximately half have followed career trajectories of the kind envisioned by the program. While this outcome is gratifying, it was also learned that some program graduates subsequently withdrew from a research-oriented academic track after many years of graduate study. That disquieting outcome underscores the need to inform aspiring veterinary scientists about the realities of a research career; to structure their graduate studies in a manner that will maximize their prospects of success; to provide them with ongoing guidance and assistance; and to reward them at a level that will ensure that they remain in training for a period sufficient to realize their career expectations.
\end{abstract}

Cornell University's College of Veterinary Medicine hosts an annual Leadership Program for Veterinary Students. The goal of the program is to identify and facilitate the career progression of individuals who have the ability and motivation to become independent research scientists and leaders in the veterinary profession. The program is an intensive learning experience that takes place during June, July, and the first two weeks of August. It combines faculty-guided student research, independent study, and small-group modules that feature interactive student-directed learning. Vocational counseling occurs throughout the program. Its purpose is to empower students to make informed choices about research and clinical training beyond the DVM degree and to assist them in reconciling personal and professional responsibilities during a protracted period of graduate study.

The Leadership Program is not limited to Cornell students; 255 individuals from 49 veterinary colleges worldwide have taken part in the program since 1990. Approximately half have been US citizens; the remainder come mainly from colleges elsewhere in the English-speaking world and from Western Europe.

A preliminary report on this initiative was published in 1999. ${ }^{1}$ Since then, the program has grown to involve groups of approximately 25 students. Its structure, too, has changed, shaped in large measure by the experiences of students and the suggestions of program consultants and module facilitators. The purpose of this report is to comment on those changes and on the career choices made by program graduates.

\section{STUDENTS}

When it was first offered in 1990, the Cornell Leadership Program had the limited objective of acquainting veterinary students with the discovery process and with careers in which research would become a significant element of the individual's professional responsibilities. In the intervening years, the number of applicants has increased substantially. That reality has persuaded the Admissions Committee to modify the student selection guidelines. The committee no longer encourages applications from students who wish to explore research as an alternative to private practice; it now targets individuals who have the potential to excel as research scientists. Such leanings are revealed in the work experience of applicants, their hobbies, and other characteristics that speak of an inquiring mind, perseverance, and an interest in the discovery process.

Applications are invited once each year, with a submission deadline in the last week of December. The program is announced through posters and letters to veterinary colleges from which Cornell has traditionally attracted successful candidates. A description of the program also is provided on the World Wide Web (http://web.vet.cornell.edu/public/research/leadership).

Some colleges have adopted procedures for acquainting applicants with the Leadership Program and assessing their capacity to benefit from it. Pre-selection mechanisms are robust at North Carolina State University, the University of Sydney, and the veterinary colleges in Hannover, Germany, and Utrecht in the Netherlands. Local counseling by faculty has been helpful to the Admissions Committee and accounts in large measure for the prominent representation of students from those colleges.

\section{SELECTION PROCESS}

The Admissions Committee is made up of the Program Director and seven members of the Cornell Veterinary College faculty. All have served as student advisors in the Leadership Program, and many have participated in the program as vocational counselors and module facilitators. In assessing candidates, the committee considers the applicant's academic record, graduate record examination (GRE) scores, research experience, personal achievements, and letters of recommendation. Proficiency in English is an additional requirement. Relevant in that connection are completion of academic courses in English, work experience in an English-speaking country, a personal essay (included in the application form), and referee comments. When proficiency in English is in doubt, the individual is interviewed by telephone before a fellowship offer is made.

Admissions Committee members assign priority scores to the individual applicants. The collated scores are then used to construct a roster from which fellowship offers are made. 
After the students have been selected, their interests are matched to available projects. ${ }^{1}$

\section{BENEFITS}

From its inception, the Leadership Program has operated on the principle that financial considerations should not limit student participation. Many students-especially those enrolled in US veterinary colleges - seek paid employment during the summer months in order to service education debts. Individuals accepted into the program receive a stipend, subsidized housing, and other benefits, including health insurance, accommodations during a field visit to Washington, DC, and meals held in conjunction with scheduled program events.

\section{HOUSING}

Participating fellows live together during the 10-week period that the program is in session. A fraternity house on the Cornell campus is reserved for their exclusive use. The accommodations are spacious, well appointed, and ensure a measure of cohesion that would be difficult to realize if students were obliged to make their own lodging arrangements. Many of the modules and social events connected with the program are scheduled at the residence, typically in the evening, when they are minimally disruptive to student research.

\section{PROGRAM STRUCTURE}

The Leadership Program emphasizes experiential learning. Participating students conduct research under the guidance of faculty mentors. They also take part in small-group modules that consider topics relevant to a research career, including emerging infectious diseases, good laboratory practice, and ethical issues connected with the proper conduct of research. A module devoted to the development of leadership skills, again in the context of a research career, is the signature event in the program. Students are encouraged to think critically, communicate effectively, and make decisions often based on sub-optimal information. ${ }^{2}$

Vocational counseling is featured prominently. Arguably, it is the most important aspect of the program. The aim of the counseling is to empower students to make informed decisions about graduate training and their careers. Informal counseling occurs frequently while the program is in session; however, four meetings address specific aspects of vocational planning in a more structured setting.

The first of these meetings explores the range of career opportunities available to veterinary graduates. Veterinarians from the academic community and from industry meet with the students. The format varies from year to year; however, counselors frequently comment on critical decisions they were obliged to make in the course of their own training. Student fellows have ample opportunity to question the counselors and to probe aspects of career planning that interest them.

This first meeting sets the stage for two other meetings held later in the program. The first focuses on advanced clinical and service training. Counselors review the US internship and residency matching systems and comment on what they consider to be superior clinical and service experiences. The second meeting has similar objectives but addresses graduate research. Several counselors, including at least one who received his or her research training in a country other than the United States, emphasize the questions individuals should ask, and the investigations they should conduct, before embarking on an extended period of graduate study. Fellows are encouraged to look beyond the subject of a research project to the quality of the learning experience; to ascertain the satisfaction of individuals presently in training; and to explore the prospective mentor's record as a research scientist and his or her capacity to sustain a research program through funding mechanisms that involve informed scientific review. The advisor's record in placing trainees in research positions of the kind envisioned by the program is an additional consideration.

A fourth counseling session addresses a subject that is of great concern to many students, namely the reconciliation of personal interests and professional responsibilities during a protracted period of graduate study. Professional couples who have successfully met the challenge comment on their strategies for achieving that objective. The meeting has been reassuring and greatly appreciated by the student fellows, many of whom will be confronted with similar challenges as their careers unfold.

Several pharmaceutical companies are both sponsors of and participants in the Cornell Leadership Program. Company representatives have provided valuable insights into research careers for veterinarians in industry. Representatives of Merck \& Company have commented on how research is organized in industry and the manner in which individuals with a veterinary degree can become productively engaged. Another module, designed by scientists and administrators at Pfizer Inc., has provided insight into drug discovery and development and the regulatory process required to bring new drugs to market.

\section{FIELD VISITS}

For many years, the National Institutes of Health (NIH) and the United States Department of Agriculture (USDA) have invited Cornell Leadership Program participants to visit their facilities in the Washington, DC, area. These visits enable students to grasp the scope and excellence of research conducted in the host institutions and the opportunities they afford for research training. Fellows prepare for the visits by conducting library research on the presentation topics, which enables them to participate actively in the discussions. The field visits have been both enjoyable and valuable from a programmatic perspective.

\section{PRESENTATIONS AND REPORTING}

A two-day research meeting is convened at the conclusion of the program. This meeting provides a forum for students to discuss their projects. Abstracts of the presentations are published in an annual report that is distributed widely to veterinary colleges, the program's sponsors, and other interested parties.

\section{NETWORKING}

Aside from its primary objective of promoting the career progression of students, the Cornell Leadership Program has encouraged the formation of a professional network among program graduates. Such a network has great potential as a career-building instrument, as well as enabling the 
individuals concerned to function effectively as members of geographically dispersed problem-solving teams. Living and working together facilitates that outcome. The strategy of relying on student-directed learning strengthens bonds that develop spontaneously between individuals who must rely on one another in their learning and in their academic assignments, as well as in their responsibilities as hosts and hostesses to facilitators and counselors who take part in the program.

The networking potential of the program has been realized through the assistance that program graduates have provided to one another. Such mentoring has extended to individuals who participated in different years. Program graduates have assisted more junior colleagues in evaluating employment prospects and have advised colleagues whose only common experience was their participation in the program. The frequency of this outcome has been remarkable and was not anticipated by the program organizers.

\section{PROGRAM EXTENSIONS}

During the 12-year period that it has been offered, the Leadership Program has grown from an initial "class" of 14 students to the present annual enrollment of 25. Although many more applicants qualify for admission, enrollment has been held at the current limit. That decision was made with a view to maintaining cohesion and to ensure that participating fellows are assigned to research projects that have high academic merit.

Similar experiences are now offered in other US veterinary colleges. Several of these were made possible through the generosity of the Merck Foundation. While not as large or as comprehensive as the program at Cornell, the newer programs can be expected to grow and to evolve in ways that will provide research and research-related experiences to a larger number of veterinary students than is presently the case.

An initiative embodying many features of the Cornell program was established at Cambridge University in 2000. The Cambridge and Cornell programs provide for student and faculty exchanges, thereby enabling a subset of participants to acquire broader experience in research and leadership training in two successive summers, one in Cambridge and one at Cornell.

As we look to the future, the expectation is that the Cornell Leadership Program will continue to evolve. More attention will be given to counseling, as mentioned elsewhere in this report. We intend to capitalize on the mentoring network composed of program "graduates," faculty, and module facilitators who have taken part in the program since 1990. The aim is to utilize it as a mentoring instrument to complement the guidance provided research leaders and department chairs and the formal training offered by human resource personnel. The network would assist potential researchers not only while they are in the program but during their graduate education and still later, after they have entered the science workforce.

\section{EVALUATION}

The Cornell program has changed significantly since 1990. Modules have been added or deleted, and other elements have been modified in an effort to improve their relevance to the program's objectives and to enhance their utility as career-building exercises. Many of these changes were suggested by students, either through solicited written comments or during an interview recorded with the entire group at the conclusion of the program. Proposals for revision were approved or modified by the program organizers, who alone were able to compare the strengths and deficiencies of elements whose structure varied from year to year.

\section{OUTCOMES}

It takes many years to ascertain the impact of a program of the kind reported here. The reasons are not far to seek. US veterinary students typically apply for admission to the Cornell Leadership Program after completing just one or two years of their professional school curriculum. Two years or more must elapse before they graduate, and up to seven additional years or longer may be required for them to complete residency training, graduate research studies, or both. When the Leadership Program was first reported in 1999,1186 students had taken part in the initiative but only 65 had graduated from veterinary college. Table 1 shows that in the intervening years, the total number of participants has grown to 255 . Of the 203 who have completed their formal education, $34(16.8 \%)$ occupy research or administrative positions in the academy, government, or industry or have comparable responsibilities elsewhere. An additional 83 graduates $(40.9 \%)$ aspire to research careers but are still in training.

Table 2 indicates that a substantial proportion of program graduates $(43.4 \%)$ entered private practice immediately after completing their veterinary education. Many did so as a definitive career decision. Others sought practice experi-

\section{Table 1: Positions currently occupied by leadership program participants}

\begin{tabular}{lc}
\hline Category & Number \\
\hline Research/Administration & 34 \\
Academic & 11 \\
Government & 5 \\
Industry & 13 \\
Other & 5 \\
Post-DVM training & 83 \\
Internship/Residency & 36 \\
Graduate research & 36 \\
Post-doctoral research & 11 \\
Private practice & 83 \\
Miscellaneous, non-veterinary & 3 \\
Veterinary student & 51 \\
Unknown & 1 \\
TOTAL & 255 \\
\hline
\end{tabular}


Table 2: Career choices made by veterinary graduates of the leadership program

Entry positiona

\begin{tabular}{lcccc}
\hline Category & Number & Practice & Institutionc & Other \\
\hline Practice & 88 & 58 & 29 & 1 \\
Intern/Resident & 66 & 20 & 45 & 4 \\
Research & 47 & 5 & 2 & 1 \\
Other & 2 & 0 & 117 & 3 \\
TOTAL & 203 & 83 & 2 & 3 \\
\hline
\end{tabular}

Subsequent position ${ }^{b}$ a. Initial appointment after graduation from college.

b. Position 1-9 years later.

c. Academy, government, or industry.

ence with a view to consolidating their veterinary education, or as a temporary expedient to reduce debt obligations. The latter subsequently undertook residency training, enrolled in graduate research programs, or pursued both as preparation for a career other than private practice. Sixty-six graduates $(32.5 \%)$ opted for internship or residency training immediately after graduation. Many did so to gain additional clinical experience before entering practice, but an even larger number subsequently pursued an academic career or a career in government or industry.

Table 2 also shows that 47 program participants accepted a research appointment immediately after graduation. The majority of these individuals $(87.2 \%)$ were still in training or had independent institutional appointments one to nine years later, when the survey was conducted. A disappointing and unanticipated revelation was that six individuals opted for practice or for a career outside of veterinary medicine after completing up to seven years of graduate study. All had initially planned an academic career. Two entered practice several years after their appointment to a tenuretrack faculty position. Their decisions to deviate from an academic trajectory were dictated by financial considerations, disillusionment with the expectations of a faculty appointment, the challenge of establishing an independent research program, or a combination of these factors.

\section{DISCUSSION}

Nowhere is the need for leadership more evident than in the health professions, where rapid advances in knowledge and technology have placed a premium on creative planning, implementation, and effective teamwork. Veterinary colleges are responding to this challenge through programs that encourage the development of leadership skills. All target students at an early stage in their professional education. A program at the University of California, Davis, ${ }^{3}$ and another at the University of Sydney promote leadership development in a generic sense. Still others, like the Cornell initiative, are more narrowly focused on guiding veterinary students into research careers.

Evaluating a program like the one reported here is an imperfect process. The central question is whether it has been influential in the career decisions made by participating students. As it transpires, approximately half the partic- ipants who have completed their veterinary college studies subsequently pursued clinical training, graduate research, or both, many as preparation for a research career. Yet that gratifying outcome cannot be ascribed with confidence to inspirational experiences provided by the Cornell Leadership Program: it may have been powerfully influenced by the student selection process. Many who were accepted into the program had already exhibited interest in the discovery process, and some had research experience. Hence, a bias toward a research commitment might be expected. However that may be, the program organizers take satisfaction in the fact that only a few respondents concluded that the program either failed to meet their expectations or had little influence on their career progression. The generally positive responses are buttressed by spontaneous comments that encourage the conclusion that the program was helpful in empowering fellows to make informed decisions about graduate education and their careers. Such comments were often made several years after the individuals had completed their veterinary education, suggesting that counseling may have had a greater impact than was initially appreciated.

Many years of graduate study are required to adequately prepare an individual for a research career, and for a tenuretrack academic position in particular. The process entails personal sacrifice and delayed gratification. It is also a financial challenge for individuals who have accumulated substantial debts during their undergraduate and veterinary college education. Reports by the National Research Council $^{4}$ and the National Academy of Sciences ${ }^{5}$ have highlighted these concerns. Both emphasized the disparity between available tenure-track positions and the number of individuals who undertake graduate studies as preparation for an academic career. The reports also commented on the obligations of faculty and training directors to counsel graduate students about the realities of the employment market.

It could be argued that vocational counseling should begin earlier, before professional students complete their college education. Leadership programs have attempted to provide such guidance. The focus of the Cornell initiative has been on encouraging participating fellows to structure their graduate studies in a manner that will maximize their prospects of competing for positions in which research will become a 
significant element of the individual's professional responsibilities. This is not sufficient, however. The survey reported here revealed that six program graduates entered private practice after completing six years or more of graduate training. That outcome points to a need for greater candor and informed guidance in advising veterinary students and veterinary graduates regarding the commitment and preparation required to excel in a research career.

The tracking survey reported here revealed deficiencies in counseling not only while the respondents were enrolled in college but also during graduate study and even later, after they had been appointed to positions of independence. The results underscore the need for counseling that focuses on the realities of a research career and the importance of encouraging veterinary graduates to seek advanced training in a nurturing and scientifically superior research environment. Linked to this is the need for individuals to remain in training for a period sufficient to realize their career objectives.

Effective mentoring is essential to a successful research career. It should begin during the formative years and continue after individuals have completed their formal education. In an academic setting, this entails not only providing advice and the financial assistance needed to establish an independent research program but also professional guidance in meeting other academic expectations, including teaching, professional services, and extension activities. ${ }^{6-9}$

The proposition that prolonged training fosters a smooth progression to a research career is at variance with observations that the period of professional training is too long and the conclusion that the nation may be educating more biomedical research scientists than the market can absorb. 4,5 That the number of individuals in training exceeds the current market is not in question; nevertheless, it could be argued that projections based on historical data do not accurately reflect the research needs of a technology-driven society. The biotechnology industry alone can be expected to create many new research positions. If the projected need for biomedical research scientists, and veterinary scientists in particular, should prove robust, then the academy might more appropriately direct its efforts at counseling trainees to explore the full range of their employment options. Simultaneously, it should ensure that scientists are trained to a level of proficiency that will maximize their capacity to realize their career objectives.

The financial implications of an extended period of postgraduate study are another concern. Here there are grounds for optimism, however. Whereas the cost of graduate education for health professionals was once borne mainly by trainees and their host institutions, third-party sponsors, such as the NIH, now provide training awards that include higher stipends and generous research allowances. The effect of this change has been to shift much of the cost of graduate study from individuals and their institutions to the federal government and industry, making it more practical for individuals to remain in training for the period necessary to realize their full potential.

\section{ACKNOWLEDGMENTS}

From its inception, the Leadership Program has been sustained by grants from federal and private-sector sponsors. It is currently supported by awards from the National Institutes of Health, Pfizer Inc., Bayer AG, Pharmacia, Inc., the Albert C. Bostwick Foundation, the Richard King Mellon Family Foundation, the Merck Foundation, the Marilyn M. Simpson Charitable Trust, and the Wellcome Trust. Special thanks to Ms. Donna Green and Ms. Diane Colf for compiling the data used in this report.

\section{REFERENCES}

1. McGregor DD. Leadership training for veterinary students. J Vet Med Educ 25:6-11, 1999.

2. Fraser DR, McGregor DD. An exercise in leadership training for veterinary students aiming for careers in biomedical research. J Vet Med Educ 29:XX-XX, 2002.

3. Moore DA, Klingborg DJ. Development and evaluation of a leadership program for veterinary students. J Vet Med Educ 28:10-15, 2001.

4. National Research Council. Trends in the Early Careers of Life Scientists. Washington, DC: National Academy Press, 1998.

5. National Academy of Sciences. Addressing the Nation's Changing Needs for Biomedical and Behavioral Scientists. Washington, DC: National Academy Press, 2000.

6. Olmstead MA. Mentoring new faculty: Advice to department chairs. CSWP Gazette 13:1, 8-11, 1993.

7. August JR. Mentoring inexperienced faculty members. J Vet Med Educ 21:82, 1994.

8. Adviser, Teacher, Role Model, Friend. Washington, DC: National Academy Press, 1997.

9. Peddy S. The Art of Mentoring: Lead, Follow, and Get Out of the Way. Westport, CT: Bullion, 1999.

\section{AUTHOR INFORMATION}

Douglas D. McGregor, MD, DPhil, is Professor of Immunology in the College of Veterinary Medicine at Cornell University, Ithaca, NY 14853. He was architect of the Cornell Leadership Program and has served as its Director since 1990. Correspondence should be directed to him at ddm7@cornell.edu.

David R. Fraser, PhD, is Professor of Animal Science in the Faculty of Veterinary Science at the University of Sydney, Australia. 